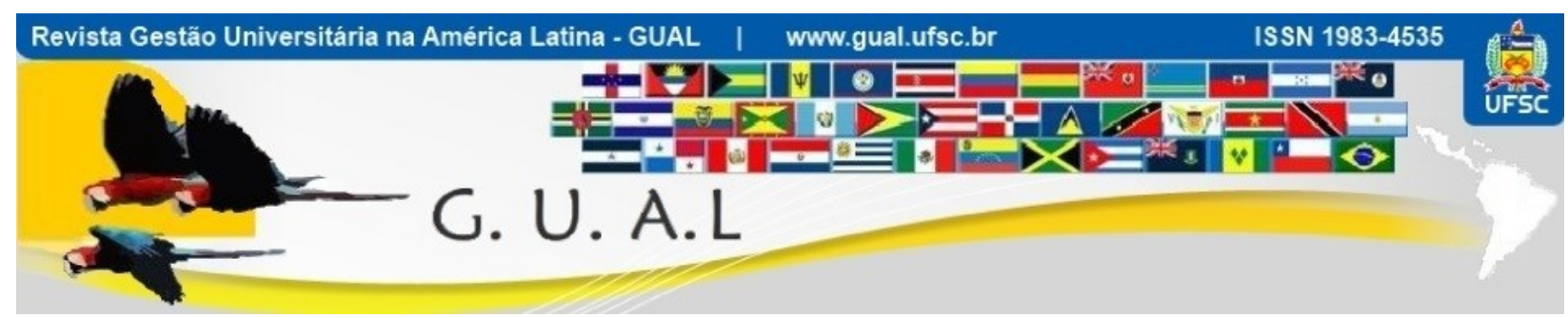

DOI: http://dx.doi.org/10.5007/1983-4535.2019v12n1p138

\title{
A SALA DE AULA COMO AMBIENTE DA DIVERSIDADE CULTURAL: PERCEPÇÃO DOS ESTUDANTES UNIVERSITÁRIOS
}

\section{THE CLASSROOM AS AN ENVIRONMENT OF CULTURAL DIVERSITY: UNIVERSITY STUDENTS 'PERCEPTION}

\begin{abstract}
Sidnei Gripa, Mestre https://orcid.org/0000-0001-8516-5821 gripa@unifebe.edu.br

Fundação Universidade Regional de Blumenau | Programa de Pós-Graduação em Ciências Contábeis e Administração Blumenau | Santa Catarina | Brasil

Júlio Cesar Lopes de Souza, Mestre https://orcid.org/0000-0003-0698-5982 juliolopes@furb.br

Fundação Universidade Regional de Blumenau | Programa de Pós-Graduação em Ciências Contábeis e Administração Blumenau | Santa Catarina | Brasil

Giancarlo Gomes, Doutor https://orcid.org/0000-0003-1174-7161 giancarlog@furb.br

Fundação Universidade Regional de Blumenau | Programa de Pós-Graduação em Ciências Contábeis e Administração Blumenau | Santa Catarina | Brasil
\end{abstract}

Recebido em 04/novembro/2017

Aprovado em 29/outubro/2018

Publicado em 02/janeiro/2019

Sistema de Avaliação: Double Blind Review

Esta obra está sob uma Licença Creative Commons Atribuição-Uso. 


\title{
RESUMO
}

Este estudo teve como objetivo verificar a percepção da diversidade cultural entre estudantes universitários. Para tal foi desenvolvida uma pesquisa exploratória, quantitativa e de corte transversal, com dados primários oriundos de questionário Survey. O questionário foi aplicado a 357 estudantes do curso de administração de duas instituições de ensino superior a partir do modelo de avaliação da Secretaria de Educação Continuada, Alfabetização e Diversidade/SECAD (2008), do Ministério da Educação e Cultura/MEC, Presotti (2011) e Rodrigues (2013). Os resultados demonstram que a diversidade é baixa na sala de aula. Por meio das respostas sócio demográficas percebeu-se que a sala de aula é predominantemente composta de jovens, solteiros de raça branca pertencentes as classes $\mathrm{C}$ e $\mathrm{B}$. Em relação a análise fatorial observou-se que apenas quinze variáveis permaneceram no modelo final agrupadas em quatro componentes, as determinantes Percepção, Relacionamento com o Grupo e Entendimento. Conclui-se que ainda há muito o que se fazer para transformar as salas de aula em ambientes acessíveis a todos.

Palavras-chave: Diversidade Cultural. Multiculturalismo. Ensino Superior. Perfil Discente.

\begin{abstract}
This study aimed to verify the perception of cultural diversity among university students. For this, an exploratory, quantitative and cross-sectional study was developed, with primary data from a Survey questionnaire. The questionnaire was applied to 357 students of the management course of two higher education institutions, based on the evaluation model of the Ministry of Education and Culture / MEC, Presotti (2011), of the Secretariat for Continuing Education, Literacy and Diversity / SECAD ) and Rodrigues (2013). The results show that diversity is low in the classroom. Through the socio-demographic answers it was noticed that the classroom is predominantly composed of young, white singles belonging to classes $\mathrm{C}$ and B. Regarding the factorial analysis, it was observed that only fifteen variables remained in the final model grouped into four components, the determinants Perception, Group Relationship and Understanding. It is concluded that much remains to be done to transform classrooms into accessible environments for all.
\end{abstract}

Keywords: Cultural Diversity. Multiculturalism. Higher Education. Student Profile. 


\section{INTRODUÇÃO}

A diversidade cultural é um tema que segue o movimento mundial pela educação inclusiva, uma ação política, cultural, social e pedagógica, em defesa do direito de todos os estudantes de estarem juntos sem discriminação, aprendendo e participando. No Brasil a diversidade cultural é amparada pela Política Nacional de Educação Especial na Perspectiva da Educação Inclusiva, que constitui em paradigma educacional fundamentado na concepção de direitos humanos, que prescreve igualdade e diferença como valores indissociáveis, e que avança em relação à ideia de equidade formal ao contextualizar as circunstâncias históricas da produção da exclusão dentro e fora da escola. (BRASIL, 2007; SECAD, 2008).

$\mathrm{O}$ avanço acelerado da tecnologia e sua adoção massiva, aumentou e privilegiou a expressão individual e acabou por incentivar o aumento do intercâmbio cultural, oferecendo novas possibilidades e gerando novas demandas. Dessa forma a própria identidade do indivíduo que compõe a sociedade se tornou diferente (CRISP; TURNER, 2011; RODRIGUES, 2013).

Sobre a identidade individual, trata-se de um conjunto de características que distinguem uma pessoa das demais dentro de um contexto social, de acordo com Nkomo e Cox Jr (1998). Esse quadro é evidentemente complexo e interconectado, com um fluxo expressivo de novos hábitos e significados sendo intercambiados. Os sujeitos passaram a se empoderar pela abundante quantidade de novos meios de expressão, que se notabilizam por serem muito disponíveis, abertos, variados e praticamente inesgotáveis, impactando diretamente na identidade individual e coletiva (LIMA, 2009; COSTA et al., 2011).

Esse cenário se reflete intensamente em todas as áreas de convivência, inclusive a educacional. As instituições de ensino passam por processo acelerado de transformação, com relações sociais mais expostas e maior aceitação das opções pessoais. A universidade se sobressai pela democracia de acesso, suas portas estão continuamente abertas a todos, independentemente das diversas origens. Esse contexto sugere estar relacionada à própria mudança de perfil dos estudantes, que aparentemente estão mais abertos à pluralidade (BUTTLAR, 1994; TARAS; ROWNEY, 2007). A diversidade, por fim, é uma característica que define a sociedade moderna, nas palavras de Crisp e Turner (2011).

Sobre as dimensões relacionadas à diversidade cultural se distingue a identidade social, composta por elementos como idade, gênero e classe social. A identidade social é o que individualiza o indivíduo no ambiente social e, ao mesmo tempo, o leva a ser incluído ou 
excluído dos grupos sociais (RODRIGUES, 2013). O mundo assume, dessa forma, as feições e as marcas da multiculturalidade, da diversidade, desafiando todos a desenvolver a capacidade de conviver com as diferenças (ELY; THOMAS, 2001).

Ao se mencionar as diferenças tornadas evidentes nesse contexto surge a necessidade de se abordar a habilidade de convivência com o diverso, a habilidade pessoal de permitir a existência de escolhas diversas, mesmo a aproximação dos indivíduos com identidades sociais diferentes. Esse cenário requer elementos comuns na dialética cotidiana, como empatia, escuta, diálogo, tolerância, entre outros (COX; BLAKE, 1991; SCHNEIDER; NORTHCRAFT, 1999; RICHARD, 2004; SARAIVA; IRIGARAY, 2009)

Esse raciocínio encontra significância se for considerado que a diversidade pode ser compreendida como um misto de pessoas com identidades de grupo diferentes dentro do mesmo sistema social, de acordo com Nkomo e Cox Jr. (1998). Os autores afirmam ainda que as perspectivas intergrupais têm sido uma das principais estruturas para o entendimento das interações humanas, envolvendo indivíduos percebendo a si mesmos como membros de uma categoria social ou sendo percebidos por outros como pertencentes a uma categoria social (NKOMO; COX JR, 1998).

Parte da abordagem dos estudos referentes a diversidade, relaciona-se com a educação e o foco nesses está voltado para a forma como os professores estão se ocupando da diversidade na sala de aula (CANDAU, 2002; GAY, 2010; CROWE; MCLEOD, 2012; CHING, 2012; AKKARI; SANTIAGO, 2013; GAY, 2013). O governo federal também contribuiu ao inserir como diretrizes obrigatórias para os cursos superiores: os conteúdos transversais de relações étnicos raciais, e para o ensino de história, e cultura afro-brasileira, africana e indígena, direitos humanos entre outras diretrizes voltadas para os estudos da diversidade cultural (SECAD, 2008).

A despeito dessa evolução na compreensão de que há diferentes identidades, que não se restringe ao âmbito das Instituições de Ensino Superior, alguns estudos indicam que há um evidente descompasso entre o que é oferecido pelas organizações e o que é esperado pelos sujeitos que a compõe, que não raramente se decepcionam e se evadem (MILLIKEN; MARTIN, 1996; SCHNEIDER; NORTHCRAFT, 1999). Essa percepção é compactuada por Nkomo e Cox Jr. (1998), que afirmam que, no geral as ações que consideram a diversidade são focadas nas intenções das organizações, não nas demandas de seus membros. 


\section{A SALA DE AULA COMO AMBIENTE DA DIVERSIDADE CULTURAL: PERCEPÇÃO DOS

Esse cenário destaca a necessidade de investigação a respeito da percepção dos estudantes a respeito da diversidade em sala de aula, ambiente da mediação cultural entre os envolvidos, algo ainda pouco explorado nos estudos disponíveis. Afinal, como a diversidade está sendo percebida e entendida sob a ótica dos estudantes universitários? Diante do exposto, o objetivo principal deste estudo é responder esse questionamento, ao identificar o perfil do estudante universitário presencial em relação à sua compreensão a respeito da diversidade, identificando suas principais demandas e aspectos que julgam positivos.

A presente pesquisa é, portanto, de relevância direta para educadores, líderes e gestores de escolas e universidades, pois, supre a lacuna ao identificar a diversidade na sala de aula e a percepção do próprio acadêmico sobre diversidade.

\section{REFERENCIAL TEÓRICO}

Apresentam-se nesta seção uma contextualização sobre o ensino superior no Brasil, bem como, a fundamentação teórica referente ao ensino superior e a diversidade, as quais são necessárias para o embasamento conceitual do problema de pesquisa.

\subsection{O DESENVOLVIMENTO DO ENSINO SUPERIOR NO BRASIL E O CURSO DE ADMINISTRAÇÃO}

O desenvolvimento da universidade no Brasil se deu de maneira descompassada em relação ao resto do mundo, dessa forma, atrasou-se de dois a três séculos em relação a diversos países do continente (SGUISSARDI, 2006). O Brasil foi um dos últimos a constituir e reconhecer oficialmente suas universidades, ainda que se levem em conta as precárias experiências isoladas de universidade em Manaus (1909) São Paulo (1910) e Curitiba (1912) (SGUISSARDI, 2006; FRANCISCO et al., 2014).

Apesar do surgimento de diversas instituições isoladas, em 1920, constituiu-se a primeira universidade no Brasil, como tentativa de comemorar o centenário da Independência (FRANCISCO et al., 2014). A primeira universidade se localizava na capital nacional por iniciativas políticas e se constituiu para receber o rei da Bélgica e lhe oferecer o título de Doutor "Honoris Causa". Resultante de uma proposta de expansão, constituiu-se o Estatuto das Universidades Brasileiras, alinhando atos para o desenvolvimento da educação superior no Brasil e instituindo bases regulatórias comandadas pelo governo (FRANCISCO et al., 2014). 


\section{A SALA DE AULA COMO AMBIENTE DA DIVERSIDADE CULTURAL: PERCEPÇÃO DOS

Até 1961, além das 22 universidades federais criadas, as escolas isoladas também acompanharam esse desenvolvimento, consolidando a integração de cursos e as ações para atender aos estudantes de nível médio que procuravam outros programas curriculares, além daqueles propostos ao desenvolvimento do País (FRANCISCO et al, 2014). As instituições de ensino superior podem ser públicas - mantidas e administradas pelo Poder Público, podendo ser federais, estaduais ou municipais; - ou privadas, em que são mantidas e administradas por pessoas físicas ou jurídicas de direito privado, com ou sem fins lucrativos (DE SOUZA et al, 2016).

Os cursos de Administração no Brasil têm uma história muito curta, principalmente se comparamos com os EUA, onde os primeiros cursos na área se iniciaram no final do século XIX, com a criação da Wharton School, em 1881 (CFA, 2016). Em 1952, ano em que se iniciava o ensino de Administração no Brasil, os EUA já formavam em torno de 50 mil bacharéis, 4 mil mestres e cem doutores por ano, em Administração (CFA, 2016). O surgimento da Fundação Getúlio Vargas (FGV) e a criação da Faculdade de Economia e Administração da Universidade de São Paulo (USP) marcaram o ensino e a pesquisa de temas econômicos e administrativos no Brasil (CFA, 2016).

Segundo dados do censo da educação superior INEP (2015), publicados em 06 de outubro de 2016, o curso de administração foi o curso que obteve o maior número de ingressantes no ensino superior em 2015, sendo 267.013 alunos. Foi o curso também com o maior número de concluintes, chegando a 124.986 alunos. O curso superior de administração, destaca-se como sendo o curso mais procurado no país (MEC, 2015).

\subsection{O ENSINO SUPERIOR E A DIVERSIDADE CULTURAL}

Temas que tratam das questões da inclusão, diversidade e responsabilidade social fazem parte do cotidiano das instituições e da população, de acordo com Jacobsen et al (2015). Observa-se um esforço crescente por parte de vários segmentos em contribuir para a definição de uma sociedade mais justa que, por meio de mudanças atitudinais, possa vivenciar a implementação de uma cultura baseada no respeito às diferenças e à valorização das pessoas. Entretanto, ainda que a diversidade seja reconhecida como relevante na formação educacional e gerencial, as visões multiculturais têm apresentado grandes tensões e questionamentos (CANEN; CANEN, 2005; DA SILVA; BRANDIM, 2008). 


\section{A SALA DE AULA COMO AMBIENTE DA DIVERSIDADE CULTURAL: PERCEPÇÃO DOS

Um dos obstáculos enfrentados na busca da convivência pacífica e tolerante relacionase à visão de que, a diferença é associada à inferioridade e desigualdade, e o "outro" - que é diferente, torna-se inferior e passa a representar uma ameaça aos padrões de ser e de viver (ELY; THOMAS, 2001). Exemplo disso são os padrões culturais, assentados nas culturas ocidentais brancas, letradas, masculinas, heterossexuais e cristãs, que estão arraigados no imaginário social e naturalizados cotidianamente nos diversos espaços de convivência humana, afetando tanto os chamados grupos minoritários quanto os pertencentes às esferas hegemônicas (DA SILVA; BRANDIM, 2008). Gay (2013), afirma que cultura e a diferença são uma parte incondicional da herança humana.

A cultura desempenha influência no comportamento das pessoas e não moldam somente os conjuntos heterogêneos dos agrupamentos sociais, mas a diversidade cultural pode simultaneamente existir e conviver no mesmo grupo (SCHNEIDER; NORTHCRAFT, 2006). Em função da diversidade dos alunos dentro das escolas de negócios em universidades, é cada vez mais importante compreender as particularidades culturais dos estudantes, uma vez que foi identificada uma clara relação entre a cultura nacional dos alunos e suas expectativas e comportamentos (GRUBER CHOWDHURY; REPPEL, 2011; JACKSON; CHAPMAN, 2012; RINGER; VOLKOV; BRIDSON, 2014). A cultura é um conjunto de significados publicamente e coletivamente aceitos por um determinado grupo de pessoas em um determinado momento (PETTIGREW, 1979). Cartwright e Cooper (1993) definem a cultura como "cola social”, que serve para ligar indivíduos e criar coesão de determinados grupos.

Multicultural e multiculturalismo são termos sociológicos que descrevem sociedades caracterizadas pela diversidade cultural, ética, religiosa ou étnica (MAXWELL ET AL., 2012). Multiculturalismo significa diferentes ideias para diferentes pessoas e instituições (CANEN; CANEN, 2005). De acordo com Canen e Canen (2005), os autores, (Canen, 1999, 2000; Canen; Moreira, 2001; Hall, 1997; Bhabha, 1998; McLaren, 2000), apontaram que as perspectivas multiculturais, geralmente, podem ser classificadas como liberais ou folclóricas, tratando da valorização da pluralidade cultural a partir do conhecimento dos costumes e processos de significação cultural, até visões mais críticas, relacionadas ao racismo, sexismo e preconceitos de forma geral.

Canen e Canen (2005), sugerem três dimensões pelas quais a identidade cultural pode ser visualizada, sendo elas: 


\section{A SALA DE AULA COMO AMBIENTE DA DIVERSIDADE CULTURAL: PERCEPÇÃO DOS

a) Identidade individual, está relacionada com a constituição dos sujeitos. Assim, por exemplo, ao se falar em uma identidade feminina, negra e pobre, está-se considerando os aspectos de gênero, raça e classe social.

b) Identidade coletiva, refere-se a algum marco da identidade percebido como central na construção das histórias de vida e das relações desiguais e preconceituosas que a atingem. Nesse caso, em algum momento, por exemplo, a identidade pode se reconhecer em termos de seu marcador racial, quando da luta pelo desafio a racismos e requisição de medidas para garantir sua representação em espaços sociais e educacionais.

c) Identidade institucional, sendo o conjunto de marcadores que caracterizam um ambiente institucional, no marco das tensões entre as identidades individuais plurais, as identidades coletivas e um projeto de instituição que se deve construir.

Dessa forma, o refinamento do conceito e da categoria identidade, considerada central no multiculturalismo, pode-se ampliar o olhar multicultural, dentro e fora do campo educacional, criando sinergias e aproximações que possam contribuir para uma maior compreensão das instituições e de seus atores, em uma perspectiva de valorização da pluralidade cultural e de desafio a preconceitos a ela relacionados (CANEN; CANEN, 2005). O conceito de identidade parece estar no âmago do entendimento da diversidade nas organizações (NKOMO; COX JR., 1998). O multiculturalismo se destaca como uma das preocupações dos estudos culturais e a diversidade de culturas e identidades, em face de relações de poder assimétricas, geram a necessidade de questionar e desafiar práticas silenciadoras de identidades culturais (DA SILVA; BRANDIM, 2008).

A maioria das faculdades e universidades de todo o mundo têm experimentado um aumento da diversificação cultural de seu corpo discente (TARAS; ROWNEY, 2007; ROBINSON; CLARDY, 2011). Os benefícios da diversidade para as instituições são grandes e indiscutíveis, mas se não forem geridos adequadamente, as diferenças culturais entre, os estudantes e o professores, podem ter efeitos adversos nas discussões em sala de aula e na dinâmica dos trabalhos em equipe (TARAS; ROWNEY, 2007; ROBINSON; CLARDY, 2011). Gay (2013), complementa que: uma vez que a cultura e a diferença são essenciais para a humanidade, devem desempenhar um papel central no ensino e na aprendizagem.

A gestão eficaz da diversidade na academia é vital e deve ser abordada em diferentes níveis (TARAS; ROWNEY, 2007; ROBINSON; CLARDY, 2011. No nível individual, os professores precisam encontrar maneiras de facilitar as discussões em sala de aula e dar apoio às equipes multiculturais (TARAS; ROWNEY, 2007). Ao nível organizacional, a 


\section{A SALA DE AULA COMO AMBIENTE DA DIVERSIDADE CULTURAL: PERCEPÇÃO DOS

administração da universidade deve identificar os elos fracos na gestão da diversidade e implementar programas que visem a redução dos efeitos negativos da diversidade (TARAS; ROWNEY, 2007).

Estudos têm mostrado que estudantes da Ásia evitam os confrontos ou a expressão de mensagens negativas, o que leva os asiáticos a serem agradáveis e dar respostas agradáveis a perguntas que possam ter respostas desagradáveis (GUDYKUNST; KIM, 1984). Lebra, (1976), reforça que os japoneses por exemplo, tentam não causar problemas para os outros e não ferir seus sentimentos. Estudantes de culturas asiáticas são mais propensos a dizer bom em vez de ótimo e não muito bom em vez de péssimo, escolhendo respostas médias por exemplo em testes que utilizam escalas do tipo Likert, diferente dos americanos que preferem dar respostas utilizando os extremos da escala (HARZING, 2006; LIM, 2003).

A preocupação com o tema da diversidade em salas de aula brasileiras é incipiente e esteve praticamente ausente ao longo de quase todo o século XX (AKKARI, SANTIAGO, 2013). Da Silva e Brandim (2008), pontuam que os estudos sobre a diversidade no Brasil nascem nas primeiras décadas do século XX, mas, os debates não contaram inicialmente com a adesão das universidades, o que vem a ocorrer somente a partir dos anos 80 e, sobretudo, dos anos 90 em diante. A temática da diversidade está pautada por fundamentos éticos, entendimento de preceitos jurídicos, conhecimento de conceitos referentes ao campo da história e geografia, da sociologia, da linguística, da antropologia, da psicologia, assim como aspectos apontados pelos estudos populacionais (AKKARI, SANTIAGO, 2013).

De uma maneira abrangente há uma percepção que se caminha a passos lentos no sentido de acolher a diversidade, sobretudo quando se considera a rapidez com que se assume práticas preconceituosas, racistas, estereotipadas ou xenofóbicas diante do "outro" (NKOMO; COX JR., 1998). E, o mais importante, apesar das conquistas alcançadas em todos os países do mundo ocidental, tais como o Brasil, as ações efetivas têm sido tímidas na maioria das instituições formadoras (incluindo as escolas e universidades) com vistas a uma educação multicultural capaz de ensinar e aprender a lidar com práticas discriminatórias (DA SILVA; BRANDIM, 2008).

\section{METODOLOGIA}

A presente pesquisa quanto ao objetivo de identificar a diversidade no curso de administração e a percepção dos acadêmicos sobre a diversidade na sala de aula enquadra-se 


\section{A SALA DE AULA COMO AMBIENTE DA DIVERSIDADE CULTURAL: PERCEPÇÃO DOS

como exploratória, devido à falta de informação do assunto estudado. Quanto aos procedimentos configura-se como estudo de caso. Yin (2010), define o estudo de caso como o entendimento em profundidade de um determinando fenômeno Em relação à abordagem de pesquisa, a mesma se enquadra como quantitativa pela utilização de técnicas estatísticas para a análise de dados.

A população do estudo corresponde a todos os acadêmicos matriculados no curso de administração de duas universidades do Vale do Itajaí no semestre de 2017-1, sendo 785 acadêmicos. A amostra correspondeu a 357 acadêmicos que representam $45,48 \%$ do total. A coleta de dados se deu por meio de questionário estruturado que foi aplicado com os acadêmicos no mês de fevereiro de 2017.

O questionário adotado é uma adaptação do modelo de avaliação da Secretaria de Educação Continuada, Alfabetização e Diversidade/SECAD (2008), órgão do Ministério da Educação e Cultura/MEC, Presotti (2011) e Rodriguês (2013), e foi dividido em duas partes. $\mathrm{Na}$ primeira parte contemplando 13 questões, consideraram-se as variáveis sócio demográficas de cada acadêmico, tais como: fase do curso, sexo, gênero, idade, raça, classe social entre outras com o objetivo de identificar o perfil sociocultural de cada acadêmico. $\mathrm{Na}$ segunda parte, procurou-se identificar a percepção dos acadêmicos em relação a diversidade na sala de aula. O questionário utilizado para a coleta dos dados, na segunda parte, foi composto por 30 questões fechadas e deveriam ser respondidas por meio de escala do tipo Likert, com pontuações variando de 1 ("Discordo totalmente") a 5 ("Concordo totalmente"). A base para o desenvolvimento foram as determinantes: percepção, relacionamento com o grupo, entendimento, experiência e comportamento conforme quadro 1.

Após a coleta dos dados, os mesmos foram tabulados em planilha de Excel e posteriormente tratados pelo software SPSS 22. Para a verificação do objetivo proposto inicialmente, foi utilizada a técnica de Análise Fatorial Exploratória - AFE que, segundo Corrar, Paulo e Filho, (p. 74, 2007), busca a identificação de dimensões de variabilidade comuns existentes em um conjunto de variáveis.

Para uma análise fatorial adequada, seguindo as considerações de Hair Jr et al (2005), deve-se seguir alguns procedimentos. Foram feitos na pesquisa os testes de Bartlett e KaiserMeyer-Olkin (KMO). No caso de Bartlett, verifica-se há correlação entre as variações, ou seja, se a matriz não é identidade. Quando ao KMO quanto mais próximo de 1 melhor, ou seja, como no modelo apresentou 0,756 , indica que a análise fatorial é adequada para a análise 


\section{A SALA DE AULA COMO AMBIENTE DA DIVERSIDADE CULTURAL: PERCEPÇÃO DOS \\ DOI: http://dx.doi.org/10.5007/1983-4535.2019v12n1p138}

das variáveis. Outro aspecto importante para a confiabilidade do modelo é o teste de Alpha de Crombach, que analisa se as variáveis dos fatores realmente pertencem ao mesmo grupo. Um valor de pelo menos 0,50 , considerando de 0 a 1 , é aceitável.

Quadro 1 Determinantes da diversidade cultural

\begin{tabular}{|c|c|c|}
\hline Determinantes & Variáveis & Autor \\
\hline Percepção & $\begin{array}{l}\text { PV1 A minha sala de aula é diversa referente a idade; } \\
\text { PV2 A minha sala de aula é diversa referente ao sexo; } \\
\text { PV3 A minha sala de aula é diversa referente ao gênero; } \\
\text { PV4 A minha sala de aula é diversa referente a orientação sexual; } \\
\text { PV5 A minha sala de aula é diversa referente ao estado civil; } \\
\text { PV6 A minha sala de aula é diversa referente a raça; } \\
\text { PV7 A minha sala de aula é diversa referente a classe social; } \\
\text { PV8 A minha sala de aula é diversa referente a religião; } \\
\text { PV9 A minha sala de aula é diversa referente a deficiência } \\
\text { mental/física/visual. }\end{array}$ & Elaborado pelos autores. \\
\hline $\begin{array}{l}\text { Relacionamento } \\
\text { com o grupo }\end{array}$ & $\begin{array}{l}\text { RV10 Eu me importo com meu grupo de sala de aula; } \\
\text { RV11 Para realizar minhas atividades eu posso contar com os } \\
\text { colegas de sala; } \\
\text { RV12 Eu me sinto à vontade para falar coisas particulares minhas } \\
\text { com meus colegas de sala; } \\
\text { RV13 Na minha sala de aula eu posso expressar abertamente minha } \\
\text { orientação sexual; } \\
\text { RV14 Na minha sala de aula eu posso expressar abertamente minha } \\
\text { religião; } \\
\text { RV15 Na minha sala de aula eu posso expressar abertamente minha } \\
\text { classe social; } \\
\text { RV16 Sinto-me incompreendido na minha sala de aula; } \\
\text { RV17 Eu me sinto um estranho na minha sala de aula; } \\
\text { RV18 Eu gosto de estar com o grupo da sala de aula. }\end{array}$ & $\begin{array}{l}\text { Adaptado de Secretaria } \\
\text { de Educação Continuada, } \\
\text { Alfabetização e } \\
\text { Diversidade/SECAD } \\
\text { (2008); Presotti (2011) }\end{array}$ \\
\hline Entendimento & $\begin{array}{l}\text { EV19 A integração da diversidade é vista por você como positiva; } \\
\text { EV20 Na sua opinião o multiculturalismo pode ser encarado como } \\
\text { um risco para a identidade nacional; } \\
\text { EV21 O Brasil é um país livre de descriminação sociocultural; } \\
\text { EV22 O desrespeito à diversidade cultural humana é um problema } \\
\text { para a educação; } \\
\text { EV23 As várias formas de descriminação e violência causam } \\
\text { impacto negativo na universidade. }\end{array}$ & $\begin{array}{l}\text { Adaptado de Secretaria } \\
\text { de Educação Continuada, } \\
\text { Alfabetização e } \\
\text { Diversidade/SECAD } \\
\text { (2008); Rodrigues (2013) }\end{array}$ \\
\hline Experiência & $\begin{array}{l}\text { EXV24 Você já sofreu algum tipo de preconceito na sala de aula; } \\
\text { EXV25 Você conhece alguém na sala de aula vítima de } \\
\text { discriminação; } \\
\text { EXV26 Você já ouviu falar em educação para a diversidade na } \\
\text { universidade }\end{array}$ & $\begin{array}{l}\text { Adaptado de Secretaria } \\
\text { de Educação Continuada, } \\
\text { Alfabetização e } \\
\text { Diversidade/SECAD } \\
(2008)\end{array}$ \\
\hline Comportamento & $\begin{array}{l}\text { CV27 Na minha sala de aula eu me apresento as pessoas que não } \\
\text { conheço; } \\
\text { CV28 Eu sou explícito e direto sobre meus desejos e necessidades } \\
\text { com os membros da sala de aula; } \\
\text { CV29 Eu peço opiniões dos membros do grupo; } \\
\text { CV30 Eu tenho ajudado na integração da diversidades em sala de } \\
\text { aula }\end{array}$ & $\begin{array}{l}\text { Adaptado de Secretaria } \\
\text { de Educação Continuada, } \\
\text { Alfabetização e } \\
\text { Diversidade/SECAD } \\
\text { (2008); Presotti (2011) }\end{array}$ \\
\hline
\end{tabular}

Fonte: Elaborados pelos autores (2017). 


\section{RESULTADOS}

Nesta seção serão apresentados os resultados da pesquisa. Todos os 357 questionários $(100 \%)$ dos respondentes foram utilizados para análise dos dados.

\subsection{ANÁLISE DAS VARIÁVEIS SOCIO DEMOGRÁFICAS}

Todos os dados dos 357 respondentes foram válidos e utilizados para a análise das variáveis demográficas. A faixa etária dos entrevistados está representada na Tabela 1. É possível observar que a grande maioria dos respondentes $(66,9 \%)$ encontra-se na faixa de 17 a 21 anos e o menor percentual $(1,7 \%)$ encontra-se na faixa etária com 37 anos ou mais.

Tabela 1 Faixa etária dos respondentes

\begin{tabular}{ccc}
\hline Idade & Frequência & Porcentagem \\
\hline 17 à 21 & 239 & 66,9 \\
22 a 26 & 91 & 25,5 \\
27 a 31 & 16 & 4,5 \\
32 a 36 & 5 & 1,4 \\
37 e acima & 6 & 1,7 \\
\hline Total & 357 & 100,0 \\
\hline
\end{tabular}

Fonte: Dados da pesquisa.

Na Tabela 2 estão sintetizados os dados dos acadêmicos no que diz respeito ao sexo. Observa-se que neste quesito uma pequena predominância do público feminino nas IES. Dos 357 respondentes, 190 (53,2\%), são do sexo feminino e 167 respondentes (46,8\%), são do sexo masculino.

Tabela 2 Sexo dos respondentes

\begin{tabular}{ccc}
\hline Sexo & Frequência & Porcentagem \\
\hline Feminino & 190 & 53,2 \\
Masculino & 167 & 46,8 \\
\hline Total & 357 & 100,0 \\
\hline
\end{tabular}

Fonte: Dados da pesquisa.

Dos 357 respondentes conforme pode-se observar na Tabela 3, 91\%, ou seja, 325 acadêmicos são solteiros. Mostrando uma alta predominância nesse quesito. O número de acadêmicos casados e com união estável não chegou a $10 \%$. 
Tabela 3 Estado civil dos respondentes

\begin{tabular}{ccc}
\hline Estado civil & Frequência & Porcentagem \\
\hline Casado & 17 & 4,8 \\
Solteiro & 325 & 91,0 \\
União estável & 15 & 4,2 \\
\hline Total & 357 & 100,0 \\
\hline
\end{tabular}

Fonte: Dados da pesquisa.

Na Tabela 4 estão sintetizados os dados dos acadêmicos no que diz respeito a raça. Observa-se uma grande predominância da raça branca na IES. Dos 357 respondentes, 329, ou seja, (92,2\%) consideram-se brancos. Apenas 5 respondentes $(1,4 \%)$ consideram-se pertencentes a raça negra.

Tabela 4 Raça dos respondentes

\begin{tabular}{ccc}
\hline Raça & Frequência & Porcentagem \\
\hline Amarela & 6 & 1,7 \\
Branca & 329 & 92,2 \\
Negra & 5 & 1,4 \\
Parda & 17 & 4,8 \\
\hline Total & 357 & 100,0 \\
\hline
\end{tabular}

Fonte: Dados da pesquisa.

$\mathrm{Na}$ Tabela 5 estão compilados os dados no que diz respeito a classe social dos respondentes. Observa-se uma predominância das classes B e C nas IES participantes da pesquisa. Mais de $90 \%$ dos respondentes consideram-se pertencentes as classes B e C. Na classe C estão $(51,8 \%)$ dos respondentes.

Tabela 5 Classe social dos respondentes

\begin{tabular}{ccc}
\hline Classe social & Frequência & Porcentagem \\
\hline Classe A & 23 & 6,4 \\
Classe B & 138 & 38,7 \\
Classe C & 185 & 51,8 \\
Classe D & 11 & 3,1 \\
\hline Total & 357 & 100,0 \\
\hline
\end{tabular}

Fonte: Dados da pesquisa.

Dos 357 respondentes conforme pode-se observar na Tabela 6, 51,5\%, ou seja, 184 acadêmicos possuem renda de $\mathrm{R} \$ 937,00$ a $\mathrm{R} \$ 1.874,00$. Uma minoria representando 31 acadêmicos $(8,7 \%)$, possui renda superior a $\mathrm{R} \$ 3.748,00$. 


\section{A SALA DE AULA COMO AMBIENTE DA DIVERSIDADE CULTURAL: PERCEPÇÃO DOS

Tabela 6 Renda dos respondentes

\begin{tabular}{ccc}
\hline Renda & Frequência & Porcentagem \\
\hline $1.875,00$ a $3.748,00$ & 103 & 28,9 \\
937,00 a $1.874,00$ & 184 & 51,5 \\
Abaixo de 937,00 & 39 & 10,9 \\
Acima de $3.748,00$ & 31 & 8,7 \\
\hline Total & 357 & 100,0 \\
\hline
\end{tabular}

Fonte: Dados da pesquisa.

Observa-se na Tabela 7, que o cristianismo predomina entre os entrevistados. Dos 357 respondentes 287 ou seja, $(80,4 \%)$ diz pertencer a esta religião. Apenas $(0,9 \%)$ dos respondentes diz pertencer ao Budismo, Islamismo e Sikhismo.

Tabela 7 Religião dos respondentes

\begin{tabular}{ccc}
\hline Religião & Frequência & Porcentagem \\
\hline Budismo & 1 & 0,3 \\
Cristianismo & 287 & 80,4 \\
Espiritismo & 7 & 2,0 \\
Islamismo & 1 & 0,3 \\
Outra & 60 & 16,8 \\
Sikhismo & 1 & 0,3 \\
\hline Total & 357 & 100,0 \\
\hline
\end{tabular}

Fonte: Dados da pesquisa.

É possível observar pelas características sócio demográficas que sala de aula das IES participantes da pesquisa apresenta pouca diversidade. Com exceção do grande equilíbrio no que diz respeito ao sexo dos entrevistados, as outras característica não demonstrarão uma equalização. A sala de aula hoje é território dos solteiros, de raça branca, na faixa etária de 17 a 21 anos, pertencentes predominantemente a classe C. Após apresentar as características da amostra entrevistada, é que são apresentados os resultados dos tratamentos multivariados da pesquisa.

\subsection{ANÁLISE FATORIAL}

Após a aplicação do questionário foi realizada através do software estatístico SPSS versão 22 a análise fatorial, com base nas considerações de Maroco (2007). Para tanto, conforme a literatura de Hair Jr. et al. (2011), considerou-se a presença de correlações significantes de 0,05 , foram verificadas 30 variáveis a partir da amostra de 357 respondentes, sendo que todas permaneceram no modelo final. A seguir a análise descritiva, na Tabela 8 . 


\section{A SALA DE AULA COMO AMBIENTE DA DIVERSIDADE CULTURAL: PERCEPÇÃO DOS

Tabela 8 Estatística Descritiva

\begin{tabular}{|c|c|c|c|}
\hline Variáveis & $\mathbf{N}$ & Média & $\begin{array}{l}\text { Desvio } \\
\text { Padrão }\end{array}$ \\
\hline PV1. A minha sala de aula é diversa referente à IDADE & 357 & 3,493 & 1,0616 \\
\hline PV2. A minha sala de aula é diversa referente ao SEXO & 357 & 4,076 & 1,0533 \\
\hline PV3. A minha sala de aula é diversa referente ao GÊNERO & 357 & 3,339 & 1,1898 \\
\hline PV4. A minha sala de aula é diversa referente à orientação SEXUAL & 357 & 3,188 & 1,1397 \\
\hline PV5. A minha sala de aula é diversa referente ao ESTADO CIVIL & 357 & 3,549 & 1,1122 \\
\hline PV6. A minha sala de aula é diversa referente à RAÇA & 357 & 2,776 & 1,1588 \\
\hline PV7. A minha sala de aula é diversa referente à CLASSE SOCIAL & 357 & 3,683 & ,9704 \\
\hline PV8. A minha sala de aula é diversa referente à RELIGIÃO & 357 & 3,266 & ,9940 \\
\hline $\begin{array}{l}\text { PV9. A minha sala de aula é diversa referente à DEFICIÊNCIA } \\
\text { MENTAL/FÍSICA/VISUAL }\end{array}$ & 357 & 2,092 & 1,1992 \\
\hline RV10. EU ME IMPORTO com meu grupo de sala de aula & 357 & 3,692 & 1,0251 \\
\hline a & 357 & 3,650 & 1,1082 \\
\hline $\begin{array}{l}\text { sinto à vontade para FALAR DE COISAS } \\
\text { RES minhas com meus colegas de sala }\end{array}$ & 357 & 3,109 & 1,3582 \\
\hline ula eu posso expressar abertamente minha & 357 & 4,008 & 1,0926 \\
\hline ninha sala de aula eu posso expressar abertamente minha & 357 & 3,944 & 1,1052 \\
\hline $\begin{array}{l}\text { inha sala de aula eu posso expressar abertamente } 1 \\
\text { CIAL }\end{array}$ & 357 & 3,941 & 1,0676 \\
\hline RV16 & 357 & 042 &, 1616 \\
\hline RV17 & 357 & 838 & 1,1473 \\
\hline RV18 & 357 & 658 & 1,1096 \\
\hline $\begin{array}{l}\text { EV19. A INTEGRAÇÃO DA DIVERSIDADE é vista por } \\
\text { POSITIVA }\end{array}$ & 357 & 3 & ,98 \\
\hline $\begin{array}{l}\text { EV20. Na sua opinião o } \\
\text { como um risco para a ID }\end{array}$ & 357 & 2,319 & 1,2104 \\
\hline país LIVRE DE DISCRIMINAÇÃO & 357 & 1,958 & 1,0391 \\
\hline $\begin{array}{l}\text { EV22. O DESRESPEITO à DIVERSIDADE CULTURAL humana é um } \\
\text { problema para a EDUCAÇÃO }\end{array}$ & 357 & 4,050 & 1,1356 \\
\hline $\begin{array}{l}\text { EV23. As várias formas de DISCRIMINAÇÃO e VIOLÊNCIA causam } \\
\text { impacto negativo na Universidade }\end{array}$ & 357 & ,132 & 1,0558 \\
\hline EXV24. Eu já sofri algum tipo de PRECONCEITO EM SALA DE AUL & 357 & 857 & 1,1919 \\
\hline $\begin{array}{l}\text { EXV25. Eu CONHEÇO alguém na sala de aula VÍTIMA DE } \\
\text { DISCRIMINAÇÃO }\end{array}$ & 357 & 129 & 1,3 \\
\hline $\begin{array}{l}\text { EXV26. Eu já ouvi falar em EDUCAÇÃO para a DIVERSIDADE na } \\
\text { Universidade }\end{array}$ & 357 & 473 & 1,2906 \\
\hline $\begin{array}{l}\text { CV27. Na minha sala de aula EU ME APRESENTO às pessoas que não } \\
\text { conheço }\end{array}$ & 357 & 090 & 1,2145 \\
\hline $\begin{array}{l}\text { CV28. Eu sou EXPLÍCITO e DIRETO sobre meus desejos e necessidades } \\
\text { com os membros da sala de aula }\end{array}$ & 357 & 3,277 & 1,1036 \\
\hline CV29. Eu pe & 357 & 3,650 & 1,1233 \\
\hline $\begin{array}{l}\text { CV30. Eu tenho ajudado na INTEGRAÇÃO da DIVERSIDADE } \\
\text { de aula }\end{array}$ & 357 & 3,216 & 1,1273 \\
\hline
\end{tabular}

Fonte: Dados da pesquisa. 
A análise descritiva aponta que a médias das variáveis estão entre 1,838 a 4,143. Já o desvio padrão menor ficou em 0,9704 e o maior em 1,3582 em uma amostra de 357 respondentes. Para verificar o grau de adequação da AFE aos dados, utiliza-se os testes de Kaiser-Meyer-Olkin (KMO) e o teste de esfericidade de Bartlett. Os resultados dos testes estão apresentados na Tabela 9.

Tabela 9 Teste de KMO e Bartlett.

\begin{tabular}{c|c|c}
\hline \multicolumn{2}{c|}{ Medida Kaiser-Meyer-Olkin de adequação de amostragem } & $\mathbf{, 7 5 6}$ \\
\hline \multirow{2}{*}{ Teste de esfericidade de } & Aprox. Qui-quadrado & 3020,836 \\
\cline { 2 - 3 } Bartlett & df & 435 \\
\cline { 2 - 3 } & Sig. &, 000 \\
\hline
\end{tabular}

Fonte: Dados da pesquisa, (2017)

A partir da análise dos dados, tem-se o valor do KMO de 0,756 , o que indica, conforme os valores de Pereira (2004) como média. O teste de esfericidade de Bartlett apresenta um valor de 3020,836 com uma significância de 0,000, assim rejeita-se a hipótese nula de que a matriz de correlação é uma matriz identidade.

As comunalidades são também resultados importantes produzidos pela AFE. Quanto mais próximas de 1, melhor o seu poder de explicação de cada fator (CORRAR; PAULO; DIAS FILHO, 2007). A Tabela 10 apresenta as comunalidades de análise.

Analisando as comunalidades apresentadas na Tabela 10, é possível observar que apenas uma variável apresentou um baixo poder se explicação (PV9). Os demais fatores apresentam um razoável poder de explicação acima de 0,50. Hair Jr et al. (2011) afirma que quando as comunalidades estão abaixo de 0,50 , há duas possibilidades de interpretação de acordo com os autores: (1) interpretar a solução como ela é e simplesmente ignorar essas variáveis, ou (2) avaliar cada variável para possível eliminação.

Outro resultado da análise fatorial exploratória é a variância total explicada. Ela determina o menor número possível de fatores que explicam o máximo de correlações entre as variáveis. Os resultados da variância total explicada estão destacados na tabela 11. 
Tabela 10 Comunalidades

\begin{tabular}{|c|c|c|}
\hline Variáveis & Inicial & Extração \\
\hline PV1. A minha sala de aula é diversa referente à IDADE & 1,000 & 666 \\
\hline PV2. A minha sala de aula é diversa referente ao SEXO & 1,000 & .609 \\
\hline PV3. A minha sala de aula é diversa referente ao GÊNERO & 1,000 &, 710 \\
\hline PV4. A minha sala de aula é diversa referente à orientação SEXUAL & 1,000 &, 707 \\
\hline PV5. A minha sala de aula é diversa referente ao ESTADO CIVIL & 1,000 &, 578 \\
\hline PV6. A minha sala de aula é diversa referente à RAÇA & 1,000 & ,608 \\
\hline PV7. A minha sala de aula é diversa referente à CLASSE SOCIAL & 1,000 & 622 \\
\hline PV8. A minha sala de aula é diversa referente à RELIGIÃO & 1,000 & 674 \\
\hline $\begin{array}{l}\text { PV9. A minha sala de aula é diversa referente à DEFICIÊNCIA } \\
\text { MENTAL/FÍSICA/VISUAL }\end{array}$ & 1,000 & ,456 \\
\hline RV10. EU ME IMPORTO com meu grupo de sala de aula & 1,000 & 678 \\
\hline $\begin{array}{l}\text { RV11. Para realizar minhas atividades EU POSSO CONTAR com } \\
\text { os colegas de sala }\end{array}$ & 1,000 & ,633 \\
\hline $\begin{array}{l}\text { RV12. Eu me sinto à vontade para FALAR DE COISAS } \\
\text { PARTICULARES minhas com meus colegas de sala }\end{array}$ & 1,000 & 642 \\
\hline $\begin{array}{l}\text { RV13. Na minha sala de aula eu posso expressar abertamente minha } \\
\text { ORIENTAÇÃO SEXUAL }\end{array}$ & 1,000 & ,753 \\
\hline $\begin{array}{l}\text { RV14. Na minha sala de aula eu posso expressar abertamente minha } \\
\text { RELIGIÃO }\end{array}$ & 1,000 & ,744 \\
\hline $\begin{array}{l}\text { RV15. Na minha sala de aula eu posso expressar abertamente minha } \\
\text { CLASSE SOCIAL }\end{array}$ & 1,000 & ,711 \\
\hline RV16. Sinto-me INCOMPREENDIDO na minha sala de aula & 1,000 & 698 \\
\hline RV17. Eu me sinto um ESTRANHO na minha sala de aula & 1,000 &, 721 \\
\hline RV18. Eu GOSTO de estar com o grupo da sala de aula & 1,000 &, 586 \\
\hline $\begin{array}{l}\text { EV19. A INTEGRAÇÃO DA DIVERSIDADE é vista por mim } \\
\text { como POSITIVA }\end{array}$ & 1,000 & ,513 \\
\hline $\begin{array}{l}\text { EV20. Na sua opinião o MULTICULTURALISMO pode ser } \\
\text { encarado como um risco para a IDENTIDADE NACIONAL }\end{array}$ & 1,000 & ,726 \\
\hline $\begin{array}{l}\text { EV21. O Brasil é um país LIVRE DE DISCRIMINAÇÃO } \\
\text { SOCIOCULTURAL }\end{array}$ & 1,000 & 670 \\
\hline $\begin{array}{l}\text { EV22. O DESRESPEITO à DIVERSIDADE CULTURAL humana é } \\
\text { um problema para a EDUCAÇÃO }\end{array}$ & 1,000 & 639 \\
\hline $\begin{array}{l}\text { EV23. As várias formas de DISCRIMINAÇÃO e VIOLÊNCIA } \\
\text { causam impacto negativo na Universidade }\end{array}$ & 1,000 & 681 \\
\hline $\begin{array}{l}\text { EXV24. Eu já sofri algum tipo de PRECONCEITO EM SALA DE } \\
\text { AULA }\end{array}$ & 1,000 & ,633 \\
\hline $\begin{array}{l}\text { EXV25. Eu CONHEÇO alguém na sala de aula VÍTIMA DE } \\
\text { DISCRIMINACCÃO }\end{array}$ & 1,000 & ,724 \\
\hline $\begin{array}{l}\text { EXV26. Eu já ouvi falar em EDUCAÇÃO para a DIVERSIDADE } \\
\text { na Universidade }\end{array}$ & 1,000 &, 516 \\
\hline $\begin{array}{l}\text { CV27. Na minha sala de aula EU ME APRESENTO às pessoas que } \\
\text { não conheço }\end{array}$ & 1,000 & 683 \\
\hline $\begin{array}{l}\text { CV28. Eu sou EXPLÍCITO e DIRETO sobre meus desejos e } \\
\text { necessidades com os membros da sala de aula }\end{array}$ & 1,000 & ,610 \\
\hline CV29. Eu peço OPINIÕES dos membros da sala & 1,000 & ,655 \\
\hline $\begin{array}{l}\text { CV30. Eu tenho ajudado na INTEGRAÇÃO da DIVERSIDADE em } \\
\text { sala de aula }\end{array}$ & 1,000 & 605 \\
\hline
\end{tabular}

Fonte: Dados da pesquisa, (2017). 


\section{A SALA DE AULA COMO AMBIENTE DA DIVERSIDADE CULTURAL: PERCEPÇÃO DOS \\ DOI: http://dx.doi.org/10.5007/1983-4535.2019v12n1p138}

Tabela 11 Variância total explicada

\begin{tabular}{|c|c|c|c|c|c|c|c|c|c|}
\hline \multirow{2}{*}{ Componente } & \multicolumn{3}{|c|}{$\begin{array}{l}\text { Valores próprios } \\
\text { iniciais }\end{array}$} & \multicolumn{3}{|c|}{$\begin{array}{c}\text { Somas de extração de } \\
\text { carregamentos ao } \\
\text { quadrado }\end{array}$} & \multicolumn{3}{|c|}{$\begin{array}{c}\text { Somas rotativas de } \\
\text { carregamentos ao } \\
\text { quadrado }\end{array}$} \\
\hline & Total & $\begin{array}{l}\% \text { de } \\
\text { variân } \\
\text { cia }\end{array}$ & $\begin{array}{l}\% \\
\text { cumulati } \\
\text { va }\end{array}$ & Total & $\begin{array}{l}\% \text { de } \\
\text { variâ } \\
\text { ncia }\end{array}$ & $\begin{array}{l}\text { \% } \\
\text { cumulati } \\
\text { va }\end{array}$ & Total & $\begin{array}{l}\% \text { de } \\
\text { variância }\end{array}$ & $\begin{array}{l}\text { \% } \\
\text { cumulativ } \\
\text { a }\end{array}$ \\
\hline 1 & 4,525 & $\begin{array}{c}15,08 \\
4\end{array}$ & 15,084 & 4,525 & $\begin{array}{c}15,08 \\
4\end{array}$ & 15,084 & 2,726 & 9,087 & 9,087 \\
\hline 2 & 3,623 & $\begin{array}{c}12,07 \\
6\end{array}$ & 27,160 & 3,623 & $\begin{array}{c}12,07 \\
6\end{array}$ & 27,160 & 2,483 & 8,277 & 17,364 \\
\hline 3 & 2,264 & 7,546 & 34,706 & 2,264 & 7,546 & 34,706 & 2,402 & 8,008 & 25,372 \\
\hline 4 & 1,698 & 5,660 & 40,365 & 1,698 & 5,660 & 40,365 & 2,181 & 7,269 & 32,641 \\
\hline 5 & 1,450 & 4,834 & 45,199 & 1,450 & 4,834 & 45,199 & 1,875 & 6,249 & 38,890 \\
\hline 6 & 1,369 & 4,564 & 49,763 & 1,369 & 4,564 & 49,763 & 1,734 & 5,781 & 44,671 \\
\hline 7 & 1,283 & 4,277 & 54,041 & 1,283 & 4,277 & 54,041 & 1,581 & 5,269 & 49,940 \\
\hline 8 & 1,148 & 3,827 & 57,868 & 1,148 & 3,827 & 57,868 & 1,566 & 5,221 & 55,162 \\
\hline 9 & 1,083 & 3,609 & 61,477 & 1,083 & 3,609 & 61,477 & 1,525 & 5,083 & 60,244 \\
\hline 10 & 1,008 & 3,361 & 64,838 & 1,008 & 3,361 & 64,838 & 1,378 & 4,594 & 64,838 \\
\hline 11 &, 890 & 2,967 & 67,806 & & & & & & \\
\hline 12 &, 822 & 2,740 & 70,546 & & & & & & \\
\hline 13 &, 749 & 2,498 & 73,044 & & & & & & \\
\hline 14 &, 732 & 2,439 & 75,483 & & & & & & \\
\hline 15 & ,706 & 2,353 & 77,836 & & & & & & \\
\hline 16 & 679 & 2,263 & 80,099 & & & & & & \\
\hline 17 & ,605 & 2,018 & 82,117 & & & & & & \\
\hline 18 & ,567 & 1,890 & 84,007 & & & & & & \\
\hline 19 & ,549 & 1,831 & 85,838 & & & & & & \\
\hline 20 & ,503 & 1,678 & 87,516 & & & & & & \\
\hline 21 & ,489 & 1,630 & 89,146 & & & & & & \\
\hline 22 & ,469 & 1,563 & 90,709 & & & & & & \\
\hline 23 & ,442 & 1,474 & 92,183 & & & & & & \\
\hline 24 & ,416 & 1,388 & 93,571 & & & & & & \\
\hline 25 &, 385 & 1,283 & 94,854 & & & & & & \\
\hline 26 & 368 & 1,227 & 96,081 & & & & & & \\
\hline 27 &, 346 & 1,152 & 97,233 & & & & & & \\
\hline 28 & ,313 & 1,042 & 98,274 & & & & & & \\
\hline 29 & 277 &, 924 & 99,199 & & & & & & \\
\hline 30 & ,240 & 801 & 100,000 & & & & & & \\
\hline
\end{tabular}

Fonte: Dados da pesquisa (2017).

É possível perceber na Tabela 11, que o modelo foi agrupado em dez fatores. Esses dez fatores com valores superiores a um, possuem poder de explicação de $64,838 \%$ da variância total. Fatores adicionais não melhorariam expressivamente a explicação da variância total.

$\mathrm{Na}$ Tabela 12, são demonstradas as cargas fatoriais que representam a contribuição de cada variável para a formação dos fatores. Utilizou-se a matriz de componentes rotacionada 


\section{A SALA DE AULA COMO AMBIENTE DA DIVERSIDADE CULTURAL: PERCEPÇÃO DOS \\ DOI: http://dx.doi.org/10.5007/1983-4535.2019v12n1p138}

dos fatores (varimax), para melhorar visualizar as cargas fatoriais representativas em cada fator e, os coeficientes abaixo de 0,5 foram suprimidos.

Tabela 12 Matriz de componentes rotacionada

\begin{tabular}{l|c|c|c|c}
\hline & \multicolumn{3}{|c}{ Componente } \\
\cline { 2 - 5 } & \multicolumn{1}{l}{1} & 2 & 3 & 4 \\
\hline PV8. A minha sala de aula é diversa referente à religião &, 789 & & & \\
\hline PV7. A minha sala de aula é diversa referente à classe social &, 748 & & & \\
\hline PV5. A minha sala de aula é diversa referente ao estado civil &, 704 & & & \\
\hline PV6. A minha sala de aula é diversa referente à raça &, 659 & & & \\
\hline $\begin{array}{l}\text { RV11. Para realizar minhas atividades eu posso contar com os colegas de } \\
\text { sala }\end{array}$ &, 760 & & \\
\hline RV10. Eu me importo com meu grupo de sala de aula &, 748 & & \\
\hline RV18. Eu gosto de estar com o grupo da sala de aula & &, 704 & & \\
\hline $\begin{array}{l}\text { RV12. Eu me sinto à vontade para falar de coisas particulares minhas com } \\
\text { meus colegas de sala }\end{array}$ &, 614 & & \\
\hline $\begin{array}{l}\text { RV13. Na minha sala de aula eu posso expressar abertamente minha } \\
\text { orientação sexual }\end{array}$ & &, 815 & \\
\hline RV14. Na minha sala de aula eu posso expressar abertamente minha religião & & &, 803 & \\
\hline $\begin{array}{l}\text { RV15. Na minha sala de aula eu posso expressar abertamente minha classe } \\
\text { social }\end{array}$ & &, 800 & \\
\hline CV27. Na minha sala de aula eu me apresento às pessoas que não conheço & & & &, 792 \\
\hline $\begin{array}{l}\text { CV28. Eu sou explícito e direto sobre meus desejos e necessidades com os } \\
\text { membros da sala de aula }\end{array}$ & & &, 722 \\
\hline $\begin{array}{l}\text { CV30. Eu tenho ajudado na integração da diversidade em sala de aula } \\
\text { CV29. Eu peço opiniões dos membros da sala }\end{array}$ & & &, 671 \\
\hline
\end{tabular}

Fonte: Dados da pesquisa, (2017).

É possível observar na Tabela 12 que optando em deixar as variáveis com coeficientes maiores que 0,5, apenas quatro componentes agregaram três ou mais variáveis. Das trinta variáveis utilizadas, apenas quinze permaneceram no modelo. A determinante Percepção, agregou as variáveis PV8, PV7, PV5 e PV6 no componente 1. A determinante Relacionamento com o Grupo, agregou as variáveis RV11, RV10, RV18 e RV12 no componente 2 e as variáveis RV13, RV14 e RV15 no componente 3. A determinante Comportamento agregou as variáveis CV27, CV28, CV30 e CV29 no componente 4. As determinantes Entendimento (EV), e Experiência (EXV), não agregaram três ou mais variáveis. 


\section{CONSIDERAÇÕES FINAIS}

Para atender ao objetivo proposto de verificar a percepção da diversidade cultural entre estudantes universitários, foi aplicada uma pesquisa Survey diretamente com 357 estudantes de administração de duas instituições de ensino superior Catarinenses. Para atender o objetivo proposto, teve-se como abordagem metodológica da pesquisa a quantitativa e a análise dos dados por meio dos tratamentos descritivos e multivariados.

A faixa etária de 17 a 21 anos foi predominante entre os respondentes, com 66,9\%. Em relação ao sexo, há uma pequena predominância do sexo feminino, 53,2\% da amostra. No que diz respeito ao estado civil, percebe-se que $91 \%$ dos respondentes consideram-se solteiros. Entre os acadêmicos de administração, a raça branca correspondeu a 92,2\% dos respondentes. Observa-se também que 51,8\% se declarou pertencente a Classe C e 38,7\% pertencente a Classe B. Há pouca variação também em relação a religião, pois, 80,4\% declararam-se pertencentes ao Cristianismo.

A partir das entrevistas, pode-se perceber que vinte e uma das trinta variáveis se mantiveram com médias significativas, baixos desvios padrão e se distribuíram entre as notas 3 e 5 da escala Likert. As exceções foram as variáveis PV6 (A minha sala de aula é diversa referente à raça), PV9 (A minha sala de aula é diversa referente à deficiência mental/física/visual), RV16 (Sinto-me incompreendido na minha sala de aula), RV17 (Eu me sinto um estranho na minha sala de aula), EV20 (Na sua opinião o multiculturalismo pode ser encarado como um risco para a identidade nacional), EV21 (O Brasil é um país livre de discriminação sociocultural), EXV24 (Eu já sofri algum tipo de preconceito em sala DE aula), EXV25 (Eu conheço alguém na sala de aula vítima de discriminação) e EXV26 (Eu já ouvi falar em educação para a diversidade na Universidade) que obtiveram médias inferiores a 3.

Em relação aos resultados da análise fatorial, pode-se perceber que ocorreram agrupamentos diferentes do modelo original sugerido. Das trinta variáveis do modelo original, apenas quinze permaneceram no modelo final limitado as coeficientes maiores que 0,5. Em relação a determinante Percepção as variáveis que permaneceram agrupadas no modelo foram: PV5 A minha sala de aula é diversa referente ao estado civil, PV6 A minha sala de aula é diversa referente a raça, PV7 A minha sala de aula é diversa referente a classe social e, PV8 A minha sala de aula é diversa referente a religião. As demais variáveis se agruparam em apenas duas e foram retiradas do modelo. 
No que diz respeito ao Relacionamento com o Grupos, apenas duas variáveis não permaneceram no modelo: RV16 Sinto-me incompreendido na minha sala de aula e, RV17 Eu me sinto um estranho na minha sala de aula. As demais variáveis foram agrupas em dois componentes: RV10 Eu me importo com meu grupo de sala de aula, RV11 Para realizar minhas atividades eu posso contar com os colegas de sala, RV12 Eu me sinto à vontade para falar coisas particulares minhas com meus colegas de sala e, RV18 Eu gosto de estar com o grupo da sala de aula, agrupadas no componente 2. Já as variáveis: RV13 Na minha sala de aula eu posso expressar abertamente minha orientação sexual, RV14 Na minha sala de aula eu posso expressar abertamente minha religião e, RV15 Na minha sala de aula eu posso expressar abertamente minha classe social, foram agrupadas no componente 3 .

As determinantes Entendimento e Experiência não obtiveram agrupamento significativo de três os mais variáveis. Finalizando a análise fatorial, a determinante Comportamento agrupou todas as quatro variáveis: CV27 Na minha sala de aula eu me apresento as pessoas que não conheço, CV28 Eu sou explícito e direto sobre meus desejos e necessidades com os membros da sala de aula e, CV29 Eu peço opiniões dos membros do grupo; CV30 Eu tenho ajudado na integração da diversidades em sala de aula.

Como limitação do trabalho, pode-se destacar as definições de população e amostra que foram feitas por acessibilidade e conveniência. Outro aspecto é utilizar outros métodos para confirmar os resultados encontrados.

\section{REFERÊNCIAS}

AKKARI, A.; SANTIAGO, M. C. A gestão da diversidade cultural no contexto educacional brasileiro. Revista Educação em Questão, v. 38, n. 24, 2013.

BRASIL. Ministério da Educação. MEC. Plano de Desenvolvimento da Educação: razões, princípios e programas. Brasília: MEC, 2007.

. Ministério da Educação. MEC. Administração e direito são os cursos com mais inscrições. 2015. Disponível em:

http://portal.mec.gov.br/index.php?option $=$ com content\&view $=$ article\&id=20110\%3Aadmini stracao-e-direito-sao-os-cursos-mais-procurados-ate-o-momento \& catid=410\&Itemid $=86$.

Acesso em 23 dez. 2016.

BUTTLAR, L. Facilitating cultural diversity in college and university libraries. The journal of academic librarianship, v. 20, n. 1, p. 10-14, 1994.

CANDAU, V. M. F. Sociedade, cotidiano escolar e cultura (s): uma aproximação. Educação \& Sociedade, v. 23, n. 79, p. 125-61, 2002. 
CANEN, A.; CANEN, A. G. ROMPENDO FRONTEIRAS CURRICULARES: o multiculturalismo na educação. Currículo sem fronteiras, v. 5, n. 2, p. 40-49, 2005.

CARTWRIGHT, S.; COOPER, C. L. The role of culture compatibility in successful organizational marriage. The Academy of Management Executive, v. 7, n. 2, p. 57-70, 1993.

COSTA, P. B. et al. Digital fluency and the use of virtual environments: the characterization of nursing students. Revista da Escola de Enfermagem da USP, v. 45, p. 1589, 2011. ISSN 0080-6234.

COX JR., T.; BLAKE, S. Managing diversity: implications for organizational competitiveness. Academy of Management Executive, v. 5, n. 3, p. 45-57, 1991.

CFA. Conselho Federal de Administração. História da Profissão. 2016. Disponível em: http://www.cfa.org.br/administracao/historia-da-profissao. Acesso em 23 dez. 2016.

CRISP, R. J.; TURNER, R. N. Cognitive adaptation to the experience of social and cultural diversity. Psychological bulletin, v. 137, n. 2, p. 242, 2011.

CROWE, K.; MCLEOD, S.; CHING, T. Y. C. The cultural and linguistic diversity of 3-yearold children with hearing loss. Journal of Deaf Studies and Deaf Education, 2012.

DA SILVA, M. J. A.; BRANDIM, M. R. L. Multiculturalismo e educação: em defesa da diversidade cultural. Diversa, v.1, n.1, p. 51-66, 2008.

JACOBSEN, A. L. et al. Desafios da inclusão de pessoas com deficiência: um projeto de responsabilidade social da Universidade Federal de Santa Catarina. Revista Gestão Universitária na América Latina-GUAL, v. 8, n. 3, p. 93-113, 2015.

DE SOUZA, I. M. et al. O Curso de Administração da Universidade Federal de Santa Catarina-o perfil dos prováveis formandos. Revista Gestão Universitária na América Latina-GUAL, v. 9, n. 1, p. 60-81, 2016.

ELY, R. J.; THOMAS, D. A. Cultural diversity at work: The effects of diversity perspectives on work group processes and outcomes. Administrative science quarterly, v. 46, n. 2, p. 229-273, 2001.

FLEURY, M. T. L. Gerenciando a diversidade cultural: experiências de empresas brasileiras. Revista de Administração de Empresas, v. 40, n. 3, p. 18-25, 2000.

FRANCISCO, T. H. A. et al. A colaboração do segmento privado da educação superior na proposta de democratização do acesso: um estudo da perspectiva sul catarinense. Revista Gestão Universitária na América Latina-GUAL, v. 7, n. 1, p. 79-105, 2014.

GAY, G. Acting on beliefs in teacher education for cultural diversity. Journal of teacher education, v. 61, n. 1-2, p. 143-152, 2010. 

$70,2013$.

Teaching to and through cultural diversity. Curriculum Inquiry, v. 43, n. 1, p. 48-

GRUBER, T.; CHOWDHURY, I. N.; REPPEL, A. E. Service recovery in higher education: does national culture play a role? Journal of Marketing Management, v. 27, n. 11-12, p. 1261-1293, 2011.

GUDYKUNST, W. B.; KIM, Y. Y. Communicating with strangers: An approach to intercultural communication. Addison Wesley Publishing Company, 1984.HARZING, Anne-Wil. Response styles in cross-national survey research a 26-country study.

International Journal of Cross Cultural Management, v. 6, n. 2, p. 243-266, 2006.

INEP. Instituto Nacional de Estudos e Pesquisas Educacionais Anísio Teixeira. Resultados de 2015 já podem ser consultados e revelam desafios para a educação superior brasileira. 2016. Disponível em: http://portal.inep.gov.br/visualizar//asset publisher/6AhJ/content/resultados-de-2015-ja-podem-ser-consultados-e-revelamdesafios-para-a-educacao-superior-brasileira?redirect $=\mathrm{http} \% 3 \mathrm{a} \% 2 \mathrm{f} \% 2 \mathrm{fportal}$.inep.gov.br $\% 2 \mathrm{f}$. Acesso em 23 dez. 2016.

JACKSON, D.; CHAPMAN, E. Non-technical skill gaps in Australian business graduates. Education + Training, v. 54, n. 2/3, p. 95-113, 2012.

LEBRA, T. S. Japanese patterns of behaviour. University of Hawaii Press, 1976.

LIM, T.-S. Language and verbal communication across cultures. Cross-cultural and intercultural communication, p. 53-71, 2003.

LIMA, T. A. A. Um olhar para a formação de formadores em contextos on-line: os sentidos construídos no discurso coletivo; A look for the formation of educators in online context: built senses in collective discourse. MARIA ELIZABETH BIANCONCINI DE, A.: Pontifícia Universidade Católica de São Paulo 2009.

MAXWELL, B. et al. Interculturalism, multiculturalism, and the state funding and regulation of conservative religious schools. Educational theory, v. 62, n. 4, p. 427-447, 2012.

MILLIKEN, F. J.; MARTIN, L. L. Searching for common threads: understanding the multiple effects of diversity in organizational groups. The Academy of Management Review, v. 21, n. 2, p. 402-34, 1996.

NKOMO, S. M.; COX JR., T. Diversidade e identidade nas organizações. In: CLEGG, S. R. et al., Handbook de estudos organizacionais, São Paulo: Atlas, 1998.

PETTIGREW, A. M. On studying organizational cultures. Administrative Science Quarterly. Qualitative Methodology, v. 24, n. 4, p. 570-581, 1979.

PRESOTTI, L. Gerenciar a diversidade cultural nas organizações: caminhos para a inclusão. 2011. 
RICHARD, O. C. et al. Cultural diversity in management, firm performance, and the moderating role of entrepreneurial orientation dimensions. Academy of management journal, v. 47, n. 2, p. 255-266, 2004.

RINGER, A.; VOLKOV, M.; BRIDSON, K. CULTURE: marketing education in the age of cultural diversity. Education+ Training, v. 56, n. 6, p. 503-520, 2014.

ROBINSON, C. C.; CLARDY, P. It ain't what you say, it's hoe you say it: Linguistic and cultural diversity in the classroom. Journal of Cultural Diversity, v. 18, n. 3, p. 101-110, 2011.

RODRIGUES, P. C. R. Multiculturalismo: a diversidade cultural na escola. 2013. Tese de Doutorado.

SARAIVA, L. A. S.; IRIGARAY, H. A. R. Políticas de diversidade nas organizações: uma questão de discurso? RAE-Revista de Administração de Empresas, v. 49, n. 3, p. 337-348, 2009.

SCHNEIDER, S. K.; NORTHCRAFT, G. B. Three social dilemmas of workforce diversity in organizations: a social identity perspective. Human Relations, v. 52, n. 11, p. 1445-1468, 1999.

SGUISSARDI, V.. Universidade no Brasil: dos modelos clássicos aos modelos de ocasião. A universidade no Brasil: concepções e modelos, 2006.

SECAD. Secretaria de Educação Continuada, Alfabetização e Diversidade. Ministério da Educação. Avaliação da Rede de Educação para a Diversidade. Edital n. 1. Brasília:

SECAD/MEC, 2008.

TARAS, V.; ROWNEY, J. Effects of cultural diversity on in-class communication and student project team dynamics: Creating synergy in the diverse classroom. International Studies in Educational Administration, v. 35, n. 2, p. 66-81, 2007. 